\title{
Environmental and social responsibility of business in the congress and exhibition industry
}

\author{
Lubov Khoreva ${ }^{1, *}$, Oksana Kosryukova $^{1}$, Karina Mikhailova ${ }^{1}$, Yana Shokola ${ }^{1}$ \\ ${ }^{1}$ The St. Petersburg State University of Economics, 29 Sadovaya str., St. Petersburg, Russia.
}

\begin{abstract}
The place of congress and exhibition activities in the system of business tourism is shown, general approaches to assessing the contribution of tourism to the destination economy are systematized and analysed in terms of their use in the meeting industry. Four basic models for estimating the multiplier effects of tourism are presented. The analysis showed that the "input-output" model has certain advantages over other models, specifically, that it allows taking sectoral features into account during the analysis, since the assessment algorithm focuses on crosssectoral links. In order to develop a methodological apparatus for assessing the contribution of congress and exhibition services to the development of a destination, a group of indicators, according to which it is advisable to carry out an assessment, has been proposed, among which are four basic groups that include specific indicators of assessment: a group of economic and social indicators; a group of indicators related to the promotion of destination on national and world markets; a group of business indicators; a group of indicators of research intensity of destination industries. Recommendations for the development of a system of training and advanced training of specialists for the congress and exhibition industry have been made.
\end{abstract}

\section{Introduction}

Nowadays, the congress and exhibition industry is regarded as an integral part of the event industry, as an industry associated with the provision of a wide range of services for organizing a variety of business, commercial, cultural, entertainment, recreational and sports events. Today, there are many definitions of the term "meeting industry". The official dictionary of the IAPCO Association (International Association of Professional Congress Organizers) defines it as an "industry for organizing business contacts", while congress, exhibition and fair events attract not only representatives (residents) of one or

\footnotetext{
* Corresponding author: $\underline{\text { luhor@inbox.ru }}$
} 
another territory (cities, destinations, etc.), but also specialists from other regions and countries with relevant professional interests, i.e. they are actually business tourists. The rapid development of the tourism industry sets the task of further improvement of the methodological approaches to assessing the contribution of business tourism in general and the meeting industry as its component to the destination economy that hosts business events. Tasks of this paper: the first one - to consider the possibility of using the existing models for assessing the multiplier effect to determine the contribution of the meeting industry to the regional economy (theoretical, methodological, and organizational aspects); the second one - the staffing of the meeting industry in the context of training specialists with the necessary competencies in the market. The analysis of the training system for the meeting industry and the perspective development of the market of additional education services and its harmonization with the demands of the labor market in the field of exhibition and fair services seem to us also relevant and requiring further methodological and organizational development.

\section{Materials and methods}

\subsection{Methods of research}

During the study, the authors used the following methods: theoretical (analysis and synthesis; generalization and systematization; the method of analogies and comparisons); empirical (studying the experience of organizing educational programs implemented taking into account the generalized labor functions of the professional standard of a specialist in organizing exhibition activities, a comparative analysis of existing programs of additional professional education of specialists for the congress and exhibition industry; systematization of statistical and factual data obtained from open sources on the development of the meeting industry in the world and in Russia; the method of transfer and adaptation of the accumulated experience of assessing the multiplier effect in tourism on the meeting industry, specifying specific groups of indicators for describing congress and exhibition services and their contribution to the regional economy).

\subsection{Empirical base of research}

As a statistical base, data and reports of the Russian Federal State Statistics Service (Rosstat) were used. The factual base of the study was the services of the system of additional professional training of various educational institutions and programs, including: schools, educational centers, seminars, etc.

As a base for analyzing the labor market requirements for training specialists for the meeting industry, the following were used: the professional standard "Specialist in Exhibition Activity in the Field of Trade and Industry Exhibitions" (adopted in November 2016, registration number 876) adopted in the Russian Federation and the draft of professional standard "Congress Specialist" for use in the Russian congress market.

\section{Results}

\subsection{General approaches to assessing the contribution of tourism to the economy: theoretical and methodological aspects}


In a modern market economy, tourism is considered not as a closed sphere, but rather as a functional cross-sectoral territorial complex. Under the conditions of globalization of the world economy, tourism began to play a prominent role in generation of the gross domestic product, national income, leveling the balance of foreign trade, creating more opportunities for employment [1].

At the same time, the tourism sector generates a significant multiplier effect, since it is directly or indirectly associated with more than 30 sectors of the economy, such as transportation, communications, construction, catering, security, cultural, recreation, sports, retail, etc.; tourism generates significant foreign exchange earnings. The destination, its cultural and infrastructural potential is one of the most important factors that determine the decision-making by potential participants regarding their participation in conferences and exhibitions. Therefore, the conference organizers should clearly understand the criteria for assessing the territory as an attractive exhibition destination [2]. At local and national levels, tourism is increasingly perceived as a possible tool for changing the future.

It is believed that for the first time, the multiplier as a certain coefficient characterizing how much the aggregated economic indicators of a particular sector of the economy change due to increased investment or a change in the labor market in the relevant sector was used by in 1931. The concept of "multiplier" today is widely used in economic theory. In general, the multiplier (macroeconomic) is a numerical coefficient that shows how many times the aggregated indicators of economic development change due to the growth of investment or production output in the analyzed sector of the economy. In general, the mechanisms for implementing the multiplier effect look very simple: the growth of production in a separate sector leads to an increase in the cost of intermediate products and services needed to serve the growing industry, which creates an impetus for the development of related industries and economic sectors. Related industries generate an increase in the volume of expenditures on the products they need, and this leads to an increase in almost all related sectors of the economy (and not only related ones, since income is already used for consumption outside the industry itself), resulting in an increase in final consumer demand [3]. The multiplier value reflects the size of the multiplier effect, taking into account the special characteristics of the economy, such as income and employment of population, stock of natural and other resources [4, a favorable business climate, the level of innovativeness of the economy, the competence component of labor resources and etc. Many studies show that tourism activities are well integrated into the regional economic system, increases regional value added, and develops institutional sector in general [5].

The multiplier in tourism is presented as a chain of effects formed by a change in the level of tourist (or related) consumption [4]. The multiplier effect in tourism is assessed with the help of special models that can be applied to the congress and exhibition industry. The effects obtained directly by the industry (tourist or other) are called direct effects. The benefits of companies representing goods and services in the industry are indirect effects; they form the total income (of tourism/destination). In turn, the induced effect is the benefits obtained from the increased demand for consumer goods as a result of an increase in household income in the region [6], which, in turn, are related to the growth of individual segments of the economy (for example, the exhibition industry and others).

When considering industry aspects, production and investment multipliers are most often used. The production multiplier determines the change in the gross output in the economy of an industry (region) with an increase in output in a separate economic sector [7]. Investment multiplier characterizes the change in output with the growth of investment in fixed capital of a separate sector of the economy. The production multiplier consists of three main components: direct effects associated with the growth of production in the sector 
(individual industry); additional effects due to cross-sectoral links; effects arising from income distribution and subsequent consumption.

When considering the influence of congress and exhibition services on the development of a destination, it seems logical to use the production multiplier, since the industry component of production and consumption of services in the industry can be traced. However, the tourism sector as a whole and the scope of congress and exhibition services are rather cross-sectoral complexes, since serving the participants in congresses, exhibitions, fairs, they provide them with diverse sets of services of such clearly defined and connected by a single process industries as transport, logistics, accommodation sector, food, recreation, culture, financial sector, security, etc. Thus, a complex chain of interconnected participants in the process of providing congress and exhibition services arises. Assessing their overall contribution using the production multiplier becomes very problematic due to a number of facts. One of the main among them, in our opinion, is the methodological aspect of assessing the multiplier effect. Note that, despite the accumulated experience, the very idea of multiplier effects in tourism is debatable both in terms of the methodological support itself and in the formation and use of the information base. In particular, methods of statistical assessment of tourist flows, the size of which affects the amount of income from tourist services and related services, do not provide sufficient information, which negatively affects the organizational and economic component of the assessment: the procedures are complicated; the result can be conditional.

In terms of methodological support, it should be noted that in the scientific literature, as a rule, four basic models for assessing the multiplier effects of tourism are considered: the economic basic model; Keynesian model; "input-output" model; ad-hoc model [8]. In addition to them, there are also other models, for example, the assessment of the multiplier effect based on the social accounting matrix.

The economic base model, although widely distributed, is limited with regard to tourism. This is due to the fact that the model and its multipliers assess the overall effects for the entire economy, not allowing for analysis at the industry level or individual types (direct, indirect, and induced) of effects [9]. Other disadvantages of the model are: the subjective division of economic activity/sectors into main and additional; the assumption that all exports have the same multiplier effect regardless of the sector. Thus, the use of such a model to assess the contribution of the congress and exhibition industry to the destination economy will be limited by the difficulty of distinguishing between the "tourist" and "congress" components, which are interconnected in the real economy through business tourism actors.

The Keynesian multiplier model is formulated as follows: the multiplier $\mathrm{N}$ indicates that an increase in the total amount of investment causes an increase in income by an amount that is $\mathrm{N}$ times greater than the increase in investment, i.e. the investment multiplier is equal to the ratio of the income increment to the investment increment. In turn, the multipliers calculated according to the Keynesian model are limited by the fact that they do not take into account sectoral interactions, which is especially important for the congress and exhibition industry as being a diversified complex (cluster).

The "input-output" model has certain advantages over the previous two models [10]. Some of them lie in the fact that it allows taking sectoral peculiarities into account during the analysis, since the assessment algorithm focuses on cross-sectoral relations (which is important for the tourist, congress and exhibition industries). It is also important that the model allows for the separation of direct, indirect and induced effects in the assessment, thereby adapting the model to the specific objectives of the analysis.

Therefore, for the field of tourism and congress and exhibition services, the "inputoutput" model looks the most attractive, allowing one to take into account certain types of 
expenses and analyze their impact on the economy in the context of the sectoral components of the complex. However, "input-output" tables require a large amount of data, which makes them time consuming and expensive to use. In 2016, in Russia, a methodical approach was developed and applied for the first time to estimating the gross value added index of the tourist industry and the percentage of gross value added of tourist industry in the Russian GDP, and the calculation was carried out using the base "input-output" tables for assessing the value added of the tourist industry based on data of 2011 .

The special model or ad-hoc model of Archer allows us to: calculate tourist multipliers for different typologies (for example, according to nationality, type of accommodation, mode of transport, motivation/purpose of the visit, etc.) and sectoral multipliers [8]; analyze direct, indirect and induced effects at different stages, different local, regional and national geographic levels; determine the direct impact on income and employment. On the other hand, in practice, it is very difficult to include all sectors of the economy in a special Archer model, since the choice of sectors to be included depends on the researcher who analyzes and, to a significant extent, on the available funding. The key problem today is that theoretically desirable approaches to assessing regional multipliers are often "practically impractical"'.

To determine the impact of the meeting industry on the economy, some countries use the methodology developed by the UN World Tourism Organization (UNWTO). The purpose of this methodology is to assess the economic value of the meeting industry and support the development of more reliable and simple tools that can be used in management practice. This methodology is based on the use of satellite (auxiliary) tourist accounts.

The Tourism Satellite Account (TSA) is a popular method of measuring the direct contribution of tourism to the national economy. The unique possibility of satellite accounts is that they allow the use of quantitative measures to determine the contribution of tourism to the country's economy [11]. Taking into account that statistical accounting in tourism is based on a rather complicated system of satellite accounts, this method can be described as the collection of information contained in 10 specialized tables, and an important aspect here is the quality of the data. In general, it is possible to specify that satellite accounts today are a theoretical method of calculation, which in real practice works with some limitations. Model limitations can be avoided by building more complex "input-output" tables [12], which, however, require even more data, the collection of which is difficult for the above reasons.

On the other hand, one of the strengths of the methodology is that it is associated with official national accounting systems. The ability to use satellite accounts is due to the fact that many countries use the International Standard Industrial Classification of Economic Activities (ISIC) to classify industries that are represented in their national accounts. This is how the economic contribution of various industries to GDP is determined. As in the case of tourism, the congress and exhibition industry is largely oriented to the demand and does not have an ISIC code. As a result, it is not positioned directly in the national accounts. Therefore, its economic contribution cannot be adequately identified. Despite the obvious attractiveness of using satellite accounts to assess the economic contribution of the meeting industry, the existing structure of tourist satellite accounts cannot fulfill this task: despite the fact that the two fields (tourism and meeting industry) are rather closely intersected, they are not identical. Moreover, most of the activities in the field of tourism are activities not related to the meeting industry, and a large percentage of events related to the meeting industry are intended for "non-tourists" (for residents). 


\subsection{Proposals for the development of a system of indicators for assessing the contribution of the meeting industry to the destination economy}

In order to assess the economic contribution of the meeting industry, it is important to understand the difference between tourists, business tourists, and participants in events living in a destination. The structure of expenses of participants in events differs from the structure of expenses of tourists (or business tourists). Meeting participants can consume both tourist goods and also spend money on registration fees and others, including nonmandatory parts of the program of the event. As an example, we present the structures of total direct costs associated with the presence of participants in events in the UK (2012). Among the categories of expenses related to tourism, participants in events most of all spend money on living - $22 \%$, restaurant services: food and beverages - $10 \%$, and air transport $-9 \%$.

The above analysis allows the authors to propose the following main groups of indicators by which it is advisable to assess the contribution of the congress and exhibition industry to the economy:

- a group of economic and social indicators: the share of income from the meeting industry in the budget of the region; incomes growth rates; the pace and volume of attracting investments in the development of the congress and exhibition infrastructure in the destination; incomes of market participants from a perspective of industries included in the scope of congress and exhibition services; incomes of market participants in related industries not directly included in congress and exhibition activities (for example, trade, communications, utilities, urban transport, security, etc.); employment of the population in the field of congress and exhibition services, creation of additional and new jobs in the industry and related industries;

- a group of indicators related to the promotion of a destination on national and world markets: an increase in brand awareness of the destination in the country and in the world; growth of investment attractiveness of the destination (innovative susceptibility); improving the position of the region in prestigious industry ratings;

- a group of business indicators: the number and amount of contracts signed at the event and after it, the amount of investment in the signed contracts; the emergence of new market participants due to the development of the congress and exhibition industry; increase in the volume of business, cultural, trade, tourist contacts with national and international partners;

- a group of indicators of the research intensity of a destination: creation of a cluster of competencies that can become the center of attraction for both new and promising technologies and highly qualified specialists in various scientific and technical fields; development of innovative industries related to industry features of congress and exhibition events; growth in the share of jobs with high intellectual potential.

Considering that in the meeting industry, the negative impact of the seasonality factor is markedly less than in the tourism sector as a whole, and the income from business tourism is markedly higher, the governments of many countries, regional and local authorities are purposefully helping to attract to its territories as many large international business events as possible, which has become a worldwide trend today. The further development of approaches to assessing the contribution of industry to the economy will make it possible to more reasonably develop strategies for the development of destinations of business tourism.

\subsection{Training of personnel for the meeting industry: the Russian market for additional education services}


We analyzed the areas of specialist training at universities in St. Petersburg and some other Russian universities in the field of exhibition activities. The analysis showed that the universities scarcely train specialists for this field of activity; the number of such universities in our region is minimal. On the other hand, there is a growing interest of the business community of the congress and exhibition industry in the development of the professional education system. There is an urgent need for trained specialists and for the development of an additional professional education system for organizing and preparing events.

In this paper, we focus on the areas of development of professional education for the congress and exhibition industry, taking into account professional standards. Professional standards set clear requirements for education and training, practical experience and other characteristics, among which, in particular, there are requirements for additional professional education. The presence of professional standards allows the employer to more clearly define the requirements for specialists, which once again emphasizes the importance and necessity of specialized education and professional development opportunities in the system of additional training [13].

Today, in the congress and exhibition field of Russia, the only professional standard "Exhibition Specialist in the Field of Trade and Industry Exhibitions" has been approved. The draft of the professional standard "Congress Specialist" is under discussion. In professional standards for each generalized labor function, some barriers are established for the subsequent possibility of the legitimate exercise of professional activity. These barriers, in our opinion, can stimulate the development of a system of advanced training of specialists.

The analysis of professional standards allows us to say that specific requirements are made for each generalized labor function in terms of additional professional education [14]. At the same time, with respect to advanced training programs, the requirements are not regulated in any way by the focus of the programs; more specific requirements that establish the approximate theme of the programs are presented only for professional retraining programs.

We have carried out a study of the current state of education for the congress and exhibition field, which made it possible to establish a relationship between possible posts and specific additional professional education programs that can be used to further increase the competence level of professionals working in the congress and exhibition sphere. With regard to additional professional education programs and professional retraining programs, we note that in Russian practice, there are various advanced training courses in event management, organization of exhibitions and congresses, but at the same time, it is very difficult to draw a direct analogy with the professional standard, clearly regulate the target audience of each program in accordance with the concept of continuity of education levels.

A study of the professional education market for the meeting industry allowed the authors to draw the following conclusions:

- many educational programs do not have a specific target audience of students;

- educational programs do not clearly establish compliance with the requirements of the professional standard;

- educational programs lean toward advanced training courses, there are nearly no offers for professional retraining;

- the majority of educational programs are related to the organization of events, while not performing some of the generalized labor functions of the professional standard for organizing the activities of exhibition venues;

- educational programs do not take into account the requirements of continuity of educational levels. 
In case of the mandatory implementation of professional standards, clear requirements will be set for the construction of a staffing system, and existing proposals on the educational market in terms of additional professional education for training of specialists for congress and exhibition activities and the event industry, in our opinion, will have to be restructured in accordance with the qualification levels and the requirements of generalized labor functions and educational programs.

\subsection{Suggestions for the development of an additional professional education system for the meeting industry}

We have formulated recommendations on the formation of a system of training and advanced training of specialists for the field of congress and exhibition activities, which can, with a certain improvement and coordination, be enshrined in national legislation and business practice through the expansion of professional standards. It is proposed to build the following system:

- establish a clear target audience for advanced training programs in accordance with the qualification levels set out in the National Framework of Qualifications and in the professional standard "Exhibition Specialist in the Field of Trade and Industry Exhibitions", and in the future, in the standard "Congress Specialist" and subsequent, in case of their development and adoption;

- within the framework of each advanced training program, establish the levels of mastering of the program; determine the possible job titles of potential students and basic (mandatory) disciplines (2-3) for each level;

- establish a clearly regulated relationship between the subjects of program lessons and the requirements of the labor functions of the professional standard at the required (expected) level of competence;

- differentiate advanced training and retraining programs, use the last for specialists who do not have the necessary basic education, calculate the duration of advanced training programs on the basis of a standard of 36 academic hours or more, calculate the duration of retraining programs on the basis of a standard of at least 250 academic hours;

- provide for the possibility of obtaining certificates for those who do not have higher education, but who have extensive professional experience and experience in the relevant activity.

Thus, it is proposed to build the logic of advanced training programs, depending on the area of business of the enterprise of the congress and exhibition activity, and to adhere to the allocation of levels within each advanced training program in accordance with the qualification levels, to establish program topics based on the study of professional standards with regard to the necessary knowledge and skills of each job function considered within the qualification level.

\section{Discussions}

Starting from 2014, the Russian Federal State Statistics Service (Rosstat) uses a collective grouping of economic activities "Tourism" proposed by the Ministry of Culture of the Russian Federation and based on the Russian Classification of Economic Activities (OKVED 2). Based on this grouping, the statistical services form official statistical information on the main economic indicators in tourism, such as employment, financial results, investments, etc. The groups of these indicators were recorded in the Order of the Ministry of Culture of 2014. 
The collective grouping includes the following industry groups of data on economic activities related to tourism: data on the accommodation of visitors in the context of such accommodation facilities as hotels and other places of temporary residence, places of shortterm residence, camping, caravans and tourist trailers, etc.; data on the activities of enterprises representing catering services (restaurants, delivery of food and ready meals, drinks); data on the activities of transport enterprises (rail, air, road, water passenger transport); data on the activities of travel agencies and tour operators, including booking services; data on activities in the field of culture (demonstration of films; events in the field of performing arts, artistic creativity, cultural events held by concert halls, theaters, museums, services of nature reserves and national parks, etc., as well as the organization of conferences and exhibitions); data on activities related to the organization of sports and entertainment events (organization of sports events, organization of recreation and entertainment, including those related to the gambling business, etc.); data on the activities of retail trade in tourist goods (retail trade in souvenirs, products of folk arts and crafts, including in art galleries, as well as trade in sports equipment and sports goods in specialized stores, etc.); data characterizing tourist activities, taking into account the specifics of Russia (organization of civil liability insurance, travel insurance, etc.).

The development of this group and the beginning of its use in the tourism sector is undoubtedly an important methodological contribution to the development of a system for assessing the impact of tourism on the regional economy, which is attractive for tourists. However, as can be seen from the submitted industry list, congress and exhibition activity itself remains outside the scope of consideration. In the collective grouping of the types of economic activity "Tourism", a separate line "organization of conferences and exhibitions" is reflected only within the framework of cultural activities. However, the question arises as to how the organization of professional (trade) exhibitions should get into the system of indicators of statistical accounting of work of enterprises in the cultural sphere?

If we start from the name of the OKVED-2 grouping listed in the Russian Classification of Economic Activity OK 029-2014 (as amended in 2018), then we can see that exhibitions recorded within this subclass do not belong to cultural exhibitions. That is, we are faced with the fact that congress and exhibition activities associated with major professional trade and fair events actually get within the framework of statistical accounting in the cultural and artistic block of exhibitions. Trade shows are a mass event, where goods, services and information are displayed and distributed on a commercial basis, and which takes place within well-defined periods, with a certain frequency and in a predetermined location. Thus, a paradoxical situation arises - in the state statistical accounting, the combination of two fundamentally different activities in the field of the exhibition industry is put methodologically: creative (cultural and artistic) and professional and industry (trade and marketing). These two types of exhibitions have a different impact on the destination economy: if art exhibitions, in turn, create tourist flows, due to which income from tourist consumption in the destination grows, then the second type of exhibition - trade and marketing, not only provide business tourists as consumers in the destination market, but also create additional factors for the development of a destination economy through the inflow of investments, the development of innovative industries, the formation of competence clusters, etc. We believe that it would be advisable to add "Activities for the organization of conferences and exhibitions" as a separate line to the collective grouping of economic activities "Tourism", which will make it possible to make an assessment of the contribution of trade exhibitions beyond the scope of "Activities in the field of culture".

\section{Conclusion}


The theoretical conclusions, suggestions, and methodological recommendations formulated in the paper made it possible to specify the approaches to assessing the multiplier effect of the meetings industry, substantiate possible directions for specifying the group of indicators to determine the contribution of the meetings industry to the regional economics. The concept of the advanced training program for the congress and exhibition industry presented in the paper can be extended to participants in the congress and exhibition services market not only in Russia but also in the CIS member states.

The materials of this paper can be useful for researchers interested in the issues of assessing the multiplier effect in tourism and the formation of an integrated system of congress and exhibition services, taking into account the competence-based approach to training of personnel.

In the process of research, new questions and problems have arisen that need further understanding and solution. It is necessary to continue the development of methodological foundations for the use of existing models for assessing the contribution of the meeting industry to the economy, as well as the development of poetic tools for such an assessment. Further work is also required to improve and expand the system of professional standards for professionals who perform various duties in organizing exhibitions, congresses, and fairs.

The paper was prepared with the support of the grant of Saint-Petersburg State University of Economics, contract No. 40-CNI for performing research works by a temporary research team of June $25,2018$.

\section{References}

1. V. Nicula, P. R. Elena, Procedia Economics and Finance, 16, 703-712 (2014) doi:10.1016/S2212-5671(14)00858-2

2. M. C. Terzi, D. P. Sakasb, I. Seimenisc, Procedia - Social and Behavioral Sciences, 73, 363-372 (2013) doi:10.1016/j.sbspro.2013.02.063

3. H. Mehlum, R. Torvik, S. Valente, Journal of Monetary Economics, 83, 90-105 (2016) doi:10.1016/j.jmoneco.2016.08.009

4. A. C. Incera, M. F. Fernández, Tourism Management, 48, 11-20 (2015) doi:10.1016/j.tourman.2014.10.016

5. G. Ferrari, J. M. Jiménez, L. Secondi, Journal of Cleaner Production, 171, 1437-1446 (2018) doi:10.1016/j.jclepro.2017.10.121

6. R. Bianchi, Annals of Tourism Research, 70, 88-102 (2018) doi: 10.1016/j.annals.2017.08.005

7. H. Saijo, Journal of Economic Dynamics and Control, 78, 1-25 (2017) doi:10.1016/j.jedc.2017.02.008

8. B. Archer, J. Fletcher, Annals of Tourism Research, 23(1), 32-47 (1996) doi.org/10.1016/0160-7383(95)00041-0

9. A. Torre, H.Scarborough, Tourism Management, 59, 621-629 (2017) doi.org/10.1016/j.tourman.2016.09.018

10. Q. Chen, E.Dietzenbacher, B.Los, C.Yang, Economic Modelling, 58, 52-63 (2016) doi:org/10.1016/j.econmod.2016.05.016

11. D. C. Frechtling, Annals of Tourism Research, 37(1), 136-153 (2010) doi:org/10.1016/j.annals.2009.08.003 Annals of Tourism Research 
12. Q. Chena, E. Dietzenbacherb, B. Losb, C. Yangc, Economic Modelling, 58, 52-63 (2016) doi:org/10.1016/j.econmod.2016.05.016

13. O. Panfilova, V. Okrepilov, S. Kuzmina, Globalization impact on consumption and distribution in society, MATEC Web of Conferences, 170, 01032 (2018) doi: 10.1051/matecconf/201817001032https://doi.org/10.1051/matecconf/201817001032

14. V. Okrepilov, E. Vasilyeva, E3S Web of Conferences, 33, 03048 (2018) DOI: https://doi.org/10.1051/matecconf/20167307020 